\title{
ARAPIRACA/AL E ITABAIANA/SE, BRASIL: APONTAMENTOS ACERCA DO PROCESSO DE INDUSTRIALIZAÇÃO EM DOIS CENTROS REGIONAIS
}

\author{
Paul Clívilan Santos Firmino ${ }^{1}$ \\ Lúcia Ferreira Lirbório ${ }^{2}$
}

\begin{abstract}
Resumo: O fenômeno industrial em Arapiraca/AL e Itabaiana/SE tem surgido através de iniciativas locais, características peculiares do povo agrestino. Pode-se dizer que a gênese industrial em Arapiraca está atrelada as atividades rurais, com as casas de farinha e as feiras livres - estas responsáveis pelo surgimento de empresários e comerciantes. Hoje com um parque industrial de destaque, ultrapassa os limites regionais. Em Itabaiana a origem industrial relaciona-se também com as atividades rurais e sua feira, bem como com as olarias. Atualmente os ramos predominantes são o ceramista e as fábricas de carroceria para caminhão. Percebe-se que a transformação para economia de mercado, possibilita analisar o processo industrial que está em implementação e conquistando espaço, mesmo a atividade agrícola ainda tendo grande importância na economia.
\end{abstract}

Palavras-chave: Industrialização; Iniciativas Locais; Desenvolvimento Econômico e Regional; Arapiraca/AL e Itabaiana/SE

\section{ARAPIRACA/AL AND ITABAIANA/SE, BRAZIL: APPOINTMENTS OF THE INDUSTRIALIZATION PROCESS IN TWO REGIONAL CENTERS}

\begin{abstract}
The industrialization in Arapiraca/AL and Itabaiana/SE has emerged through local actions, peculiar characteristics of 'agrestino' people. It's possible to say that the industrial genesis in Arapiraca is bonded to rural activities, with the flour mills and street markets which are causes of the arising of businessmen and traders. Now it holds a great industrial park, it overcomes the regional limits. The Itabaiana industrial origin also relates to rural activities and its fair, as well as the potteries. Currently the predominant branches are the potter and the body of factories to truck. It's noticed that the transformation economy to market, allows analyze the industrial process that is being implemented and conquering space, even agricultural activity still having great importance in the economy.
\end{abstract}

Keywords: Industrialization; Local Initiatives; Economic and Regional Development; Arapiraca/AL and Itabaiana/SE

\section{ARAPIRACA/AL Y ITABAIANA/SE, BRASIL: APUNTES ACERCA DEL PROCESO DE INDUSTRIALIZACIÓN EN DOS CENTROS REGIONALES}

Resumen: El fenómeno industrial en Arapiraca/AL y Itabaiana/SE ha surgido a través de iniciativas locales, características peculiares del pueblo agrestino. Se puede decir que la génesis industrial en Arapiraca está vinculada a las atividades rurales, con las casas del harina

\footnotetext{
${ }^{1}$ Doutorando do Programa de Pós-Graduação em Geografia Humana/PPGH da Faculdade de Filosofia, Letras e Ciências Humanas/FFLCH da Universidade de São Paulo/USP, linha de pesquisa "Território, Economia e Dinâmicas Regionais". E-mail: pcfirmino@usp.br

${ }^{2}$ Doutora em Ciências - Geografia Humana pelo Programa de Pós-Graduação em Geografia Humana/PPGH da Faculdade de Filosofia, Letras e Ciências Humanas/FFLCH da Universidade de São Paulo/USP. Professora Doutora do Instituto Federal de Pernambuco/IFPE. E-mail: lucialirborio@usp.br
} 
y las ferias libres - estas responsables por el surgimiento de empresarios y comerciantes. Hoy con un parque industrial destacado, supera los limites regionales. En Itabaiana el origen industrial se relaciona también con las atividades rurales y su feria, así como con las alfarerías. Actualmente las ramas predominantes son el ceramista y las fábricas de carrocería para camiones. Se percibe que la transformación a la economía de mercado, posibilita analizar el proceso industrial que está en implementación y conquistando espacio, incluso la actividad agrícola teniendo gran importancia en la economía.

Palabras claves: Industrialización; Iniciativas Locales; Desarrollo Económico y Regional; Arapiraca/AL y Itabaiana/SE

\section{PRIMEIRAS PALAVRAS}

Diversas iniciativas referentes ao processo de industrialização presentes no Nordeste do Brasil, atreladas aos apoios de investimentos de alguns órgãos específicos (a exemplo da SUDENE $^{3}$ ), desmistificam visões errôneas acerca da realidade nordestina e suas respectivas cidades, destacando aquelas localizadas na sub-região Agreste. Dentre as visões equivocadas e muitas vezes errôneas, tem-se a do Nordeste como região problema.

A indústria presente na região era praticamente, até meados do decênio de 1950, direcionada ao setor têxtil, que passou a se desenvolver nas últimas décadas do século XIX, mais precisamente no ano de 1882. Seu nascimento, principalmente nas proximidades dos portos (com exceções, como a Fábrica da Pedra em Delmiro Gouveia/AL, no Sertão alagoano), deve-se em parte ao surto algodoeiro e a expansão que o mercado brasileiro de algodão vinha conquistando.

Trilhando pelas décadas seguintes, surgiram diversos ramos industriais, como o beneficiamento de óleos vegetais, o ceramista, com gênese nas olarias, destacando no interior sergipano a cidade de Itabaiana. Atrelado a estas surgiram indústrias de calçados e vestuários $^{4}$, as de fumo, espalhadas pelo interior, com destaque para a cidade de Arapiraca no interior alagoano, bem como Cruz das Almas/BA e Lagarto/SE.

Então, é possível observar que o Nordeste vai aos poucos passando de região tradicionalmente produtora de bens não duráveis para uma especialização industrialmente que começava a produzir bens intermediários, cite-se neste sentido na Bahia o polo petroquímico

\footnotetext{
${ }^{3}$ Foi criada em 1959, como resultado do Grupo de Trabalho para o Desenvolvimento do Nordeste/GTDN, a Superintendência do Desenvolvimento do Nordeste/SUDENE, órgão responsável por intervir economicamente na região e abrir espaço, principalmente, para uma maior integração no que concerne ao processo industrial nordestino.

${ }^{4}$ É possível notar, de acordo com Andrade (1974, p. 120), que "da mesma forma que a indústria de confecções, inicialmente mera atividade artesanal e hoje indústria de grande importância, como uma decorrência do desenvolvimento da indústria têxtil, a indústria de calçados, que tem grande importância na região, desenvolveuse em consequência da existência de inúmeros curtumes".
} 
de Camaçari. No Maranhão tem-se o complexo minero-metalúrgico, o polo de fertilizantes em Sergipe, o complexo da Salgema no estado de Alagoas entre outros (ARAÚJO, 1997). São exemplos, que fortalecem o grande potencial das sub-regiões nordestinas (Litoral Oriental e Zona da Mata, Agreste, Litoral Setentrional e Sertão, Meio Norte, conforme Andrade - 1998), cada uma apresentando características singulares.

Com o nascimento da indústria a economia passa a sofrer algumas mudanças e, paralelamente, contribui para o desenvolvimento regional e econômico, sendo que "este depende, pois, especialmente da rapidez e do modo como se processa a transferência de força de trabalho da economia natural para a economia de mercado" ${ }^{5}$ " (RANGEL, 2012, p. 184). Rangel ainda afirma ser preciso encarar o processo industrial como forma de substituir as diversas importações e, consequentemente, levar o país a se industrializar.

Assim, se apoderando do processo de industrialização como elemento fundamental para desenvolver o Nordeste, tirando-a do atraso econômico acumulado desde a invasão dos portugueses, faz-se necessário buscar a gênese do seu processo industrial, enfatizando aqui a discussão no que se refere à sub-região Agreste, sobressaindo às cidades de Arapiraca/AL e Itabaiana/SE, direcionando o presente artigo a analisar a gênese do fenômeno industrial mediante as iniciativas locais.

\section{Notas do processo de industrialização no Nordeste brasileiro}

Por volta da década de 1950 o Nordeste brasileiro, uma das regiões menos desenvolvidas e com altos índices de pobreza, apresentava uma economia com baixo grau de desenvolvimento, reflexo não somente dos fatores climáticos, como também de uma herança de um passado recente - diga-se o domínio das grandes lavouras agroexportadoras e seus proprietários e detentores de terras - e da fraca industrialização, que por sua vez estava em ligeiro crescimento na região Sudeste do país.

No que concerne à região Sudeste, o geógrafo Mamigonian (2009), aponta que a indústria paulista após os anos de 1930, tornou-se o centro do país, paralelamente à continuidade da inserção do Brasil ao centro do sistema mundial capitalista ${ }^{6}$ (EUA etc.), para

\footnotetext{
5 "No processo de industrialização, a economia do país, no que diz respeito ao emprego de fatores de produção, divide-se em duas partes: a economia natural (combinada e complexa) e, suas formas primária (ou agrícola) e secundaria (ou urbana); a economia de mercado, caracterizada pela divisão social do trabalho, que por sua vez se subdivide em privada e pública. A industrialização implica um fluxo de recursos de produção da economia natural à de mercado. A primeira diminui e a segunda se expande" (RANGEL, 2012, p. 122).

${ }^{6}$ Esse sistema faz com que aqueles que mais acumulam capitais enfrentem uns aos outros, "exige que os acumuladores realizem os lucros provenientes da atividade econômica, agindo contra os esforços competitivos de outros" (WALLERSTEIN, 2001, p. 55).
} 
em seguida começar um desenvolvimento voltado ao comércio da própria região. Enquanto se observava o desenvolvimento dessa parte do Brasil, o restante do território nacional ficava meio que marginalizado.

Trilhando por este caminho, Furtado (2009) mostra que o Sudeste se industrializava, enquanto o Nordeste se consolidava como a grande "área problema" do hemisfério ocidental. Essa ideia do Nordeste como região problema tem sido desconstruída diante das várias iniciativas de industrialização presentes nos recantos das terras nordestinas, algumas iniciativas locais, surgidas antes da SUDENE e que puderam ser fortalecidas, e outras criadas a partir do surgimento da mesma. Posteriormente, essas iniciativas atreladas ao apoio da SUDENE e outros investimentos na região, desmentiriam as visões errôneas sobre o Nordeste,

Nordeste região problema, Nordeste da seca e da miséria, Nordeste sempre ávido por verbas públicas, verdadeiro poço sem fundo em que as tradicionais políticas compensatórias de caráter assistencialista só contribuem para consolidar velhas estruturas sócio-econômicas e políticas perpetuadoras da miséria (ARAÚJO, 1997, p. 13).

Diante do baixo dinamismo industrial apresentado no Nordeste, por exemplo, foi criada em 1959, pelo Grupo de Trabalho para o Desenvolvimento do Nordeste/GTDN, a SUDENE, órgão responsável por intervir economicamente na região e abrir espaço, principalmente, para uma maior integração no que concerne ao processo industrial nordestino. Era, portanto, o setor de maior preocupação do referido órgão, "é que, por motivos de ordem histórica e geográfica, a frequência de emprêsas marginais é muito mais aí, do que nas demais regiões, tanto na indústria quanto na agricultura" (RANGEL, 1959, p. 429). Foram feitos estudos a respeito da presença ou ausência de indústrias na região, "considerando-as tradicionais, e procurou estimular as empresas viáveis economicamente a modernizarem e ampliarem os seus estabelecimentos" (ANDRADE, 1993, p. 44).

A agricultura nos moldes tradicionais e os produtos tradicionais dessa agricultura tem perdido espaço, tanto no Nordeste como a nível nacional, mas têm-se complexos agroindustriais muito fortes e que de certa forma reflete alguns dos impactos da industrialização na agricultura, tornando-se importante para o aumento da produção e da economia regional e do país. Passando aos poucos de uma região tradicionalmente produtora de bens não duráveis para uma região que se especializava industrialmente e que começava a produzir bens intermediários, vindo fortalecer o grande potencial presente nas sub-regiões nordestinas, cada uma com suas diversidades. 
A indústria no Nordeste brasileiro para poder criar e se firmar com uma base econômica sólida, teria então que se basear, segundo mostra Araújo (1984), em indústrias de base e indústrias que aproveitassem matérias-primas regionais. Então, seria preciso manter-se forte, de maneira que a atividade industrial garantisse uma autonomia no crescimento da própria região.

Anterior a SUDENE, até meados da década de 1950, o que prevalecia no que diz respeito ao setor industrial, estava direcionado para a indústria têxtil, que passou a se desenvolver nos anos de 1882 onde,

As primeiras fábricas de tecidos que vingaram, que conseguiram sobreviver até os nossos dias surgiram ou no meio rural em pequenos centros urbanos do interior onde os comerciantes compravam o algodão para exportar [...] ou surgiram nos pequenos portos onde o algodão era exportado para a Europa (ANDRADE, 1970a, p. 95).

O nascimento desse tipo de indústria na região, principalmente nas proximidades dos portos, deve-se em parte ao surto algodoeiro e, consequentemente, a expansão que o mercado brasileiro de algodão vinha conquistando desde as últimas décadas do século XIX, o que veio permitir "a expansão do mercado e o desenvolvimento de pequenas fábricas localizadas em várias cidades do Nordeste" (ANDRADE, 1974, p. 116).

Observa-se que a ocupação regional e o seu sistema econômico se fez a partir do açúcar e, posteriormente, com o algodão ${ }^{7}$, fazendo com que os principais centros urbanos fossem ligados com outros centros de grandes destaques no interior. Nas áreas mais distantes dos portos e dos grandes centros havia dificuldades para escoarem suas produções,

Nestes municípios mais distantes, encontramos unidades produtoras voltadas inteiramente para o autoconsumo, vivendo à margem da atividade comercial, e unidades em que a maior porção da produção destina-se ao autoconsumo, mas que comercializa os excedentes da produção agrícola, vendendo-as a comerciantes que os adquirem na própria localidade ou nas feiras realizadas nas vilas e povoações mais próximas (ANDRADE, 1974, p. 133).

Surge juntamente com a indústria têxtil nascente, o beneficiamento de óleos vegetais, com particular destaque para o próprio algodão, do qual eram retirados os caroços para tal fim. A cidade de Campina Grande - PB, era um dos centros que possuíam o maior número de estabelecimentos na produção de óleos, além é claro de se destacar no que se referia à

\footnotetext{
${ }^{7}$ Esses dois ramos industriais foram os primeiros a estimular o crescimento econômico não só do mercado externo como do próprio mercado interno que se formava. Dos dois ramos o de maior destaque para o interior nordestino foi justamente o que diz respeito à indústria de tecidos, isso se deve em parte ao fato de que grande parte da "população não tinha condições de adquirir tecidos importados e como decaía a confecção artesanal de tecidos, a produção têxtil nordestina encontrou um mercado expressivo e numerosas fábricas foram implantadas" (ANDRADE, 1993, p. 35).
} 
indústria de couros, que é uma tradição na região. Ao seu lado sobressaem, por exemplo, Caruaru/PE e Alagoinhas/BA, cidades que desempenham funções centrais nas suas subregiões. Guiando-se por esse caminho, Andrade (1993), aponta que,

O processo de industrialização do Nordeste iniciou-se na segunda metade do século XIX. Ele estava ligado à agricultura da cana-de-açúcar e do algodão, desenvolvendo a implantação de usinas de açúcar e de fábricas de fiação e tecelagem [...]. No início do século XX foram implantadas fábricas de extração do óleo de sementes de algodão, de mamona e de oiticica. As fábricas têxtis foram aperfeiçoadas, beneficiando fibras de outras plantas como a agave e o caroá. Este surto industrial desacelerou-se nos meados do século XX, mas foi reativado após a implantação da Sudene (ANDRADE, 1993, p. 22).

Além da indústria açucareira, da têxtil, de beneficiamento de óleos vegetais e a de couros - já que o Nordeste tem forte importância no que diz respeito à pecuária, estão fortemente presentes os curtumes industriais - outras foram surgindo, a exemplo das indústrias ceramistas - que tiveram suas origens nas olarias -, indústrias de fumo espalhadas pelo interior - com destaque para a cidade de Arapiraca/AL -, indústrias de calçados, vestuários entre outras.

Com o passar do tempo, a maioria dos centros urbanos, principalmente aqueles que queriam atrair indústrias, foram mudando e criando condições para que diversas indústrias dos mais variados ramos se instalassem em suas cidades, e, consequentemente, favorecendo a indústria nascente, graças em parte as facilidades que o Nordeste tinha e tem a oferecer, desde a matéria prima, mão-de-obra, transporte e tantas outras condições favoráveis à consolidação e surgimento de certas indústrias.

A indústria nordestina de forma geral foi uma extensão da industrialização do Brasil,

No final dos anos 50, com a integração física do mercado nacional e a concorrência das indústrias do Sudeste do país, as fábricas regionais, obsoletas tecnologicamente, entraram em crise, fechando suas portas ou se "reestruturando" apoiadas no plano de industrialização regional do governo federal por meio da Sudene, criada em 1959 (LIMA, 1997, p. 144).

Com a tardia industrialização nordestina foi observado nos anos posteriores à criação da SUDENE, uma dependência externa dessa industrialização, indo de encontro com a proposta de substituir importações e de manter forte comando pelo empresariado regional e local. Pode-se dizer que grande parte dessa dependência deve-se a baixa modernização tecnológica presente nas poucas indústrias, o que diminui a competitividade da mesma no mercado nacional, que de acordo com Lima (1997, p. 145), “essas fábricas passaram a 
produzir comprando matérias-primas e maquinarias do Sul e Sudeste, regiões para onde destinavam parte da produção, assim como para o mercado externo".

Junto com as demais regiões brasileiras, o Nordeste tinha que buscar meios de aumentar sua produção e diminuir suas importações, tendo na indústria o principal responsável, visto que,

A substituição implica industrialização, ou seja, intensificação da divisão social do trabalho [que por sua vez é essencial para o desenvolvimento], redistribuição da população entre os setores agricultura, manufatura e serviços, e profundas mudanças tecnológicas em toda a produção (RANGEL, 2012b, p. 87).

Faz-se necessário atentar para uma população que está às margens da industrialização, na verdade, vem antes dela, que são as populações agrícolas. É preciso olhar para essa população não como forma de excluí-las do processo industrial, mas antes de tudo de integrálas, substituindo uma produção individual por uma social. Por um lado é preciso fornecer bens agrícolas em maiores quantidades e de outro lado diminuir a população presente na agricultura, pois existe uma população ociosa que não está contribuindo no aumento da produção agrícola,

Falando de modo sucinto, a "manufatura" e os serviços são novas formas de aplicação de parte do tempo de trabalho da população que antes estava na "agricultura" [...] o que não está clara é a natureza da mudança estrutural que se opera dentro do "setor agrícola" nas condições da industrialização (RANGEL, 2012b, p. 89).

Apesar de a atividade agrícola está sempre à frente da atividade industrial como fonte econômica para os estados nordestinos, não se pode negar o seu crescimento nas últimas décadas do século passado e início do século presente - para Rangel (2012b, p. 49) “o crescimento de qualquer economia se faz pela expansão de suas 'indústrias', ou atividades 'tardias', em um perpétuo esforço para ajustar a estrutura de oferta à de demanda -, bem como no que se refere à criação de emprego e renda para a população ${ }^{8 \%}$. Andrade (1974) aponta que é preciso levar em consideração duas fases de desenvolvimento industrial quando

\footnotetext{
${ }^{8}$ Muitas vezes o baixo grau de emprego nas indústrias com uma mão-de-obra local, deve-se em parte, a uma baixa qualificação dessa mão-de-obra, trazendo de fora pessoas especializadas em certos ramos, que são ausentes onde à indústria se instala. "Uma das metas da Sudene foi o desenvolvimento industrial, esperando que a indústria possibilitasse a criação de novos empregos, a fim de reter, na região, a mão-de-obra que vinha migrando de forma muito intensa para o Sudeste e o Sul do país" (ANDRADE, 1993, p. 22).
} 
se pretende estudar as atividades industriais da região: uma que ocorreu a partir das duas últimas décadas do século XX e outra mediante a política desenvolvimentista da SUDENE 9 .

O Nordeste de fato passou a ser atraente para aqueles que estavam vendo na região uma montoeira de possibilidades de instalarem suas indústrias. Em um primeiro momento, de um lado tinha-se uma vasta mão-de-obra à disposição, muito barata, diga-se de passagem, e de outro lado os incentivos fiscais como forma de industrializar a região ${ }^{10}$. Segundo Lima (1997),

As grandes cidades do Sul e Sudeste assistem à transferência de plantas industriais para cidades menores do interior, outros estados e regiões, em busca do 'custo chinês': mão-de-obra barata, trabalhadores desorganizados, incentivos espaciais e logísticos frente à exportação. Tal processo se verifica, sobretudo, nos setores industriais, sendo mais visível nos que utilizam largamente trabalho intensivo, mesmo com as inovações tecnológicoorganizacionais: o têxtil, o de vestuário e o de calçados (LIMA, 1997, p. 141-142).

De um lado, esse processo de industrializar a região Nordeste apoiado nos objetivos traçados pela SUDENE, foi benéfico no sentido de aumentar a produção de certas mercadorias atenuando importação, criação de possibilidades de empregar uma mão-de-obra mais qualificada nos vários setores, criação de cursos universitários e técnicos - muito limitados, o que não atendia a população como um todo -, bem como o surgimento de serviços diversos e de um comércio mais consolidado, gerando assim mais renda para os estados e municípios. Posteriormente, o que se nota é uma intensificação do trabalho, com custos cada vez menores da mão-de-obra empregada, uma competitividade bastante forte e regras e normas comandadas por um mercado externo.

Por outro lado, a industrialização proposta não foi capaz de empregar o contingente de mão-de-obra sem qualificação, muito menos segurar essa população, não impedindo que a mesma migrasse para outras regiões. Portanto, era preciso que "ao mesmo tempo em que se estimulava a implantação de indústrias, deveria ter sido difundido o ensino técnico industrial e de serviços para preparar as classes menos favorecidas para o trabalho qualificado" (ANDRADE, 1993, p. 24).

\footnotetext{
${ }^{9}$ Para Andrade (1974, p. 127), "se analisarmos os resultados da atuação da SUDENE no setor de industrialização observaremos que ela vem não só contribuir para a instalação de novas indústrias no Nordeste, como também para financiar a ampliação e a modernização das indústrias tradicionais aqui existentes".

${ }^{10}$ Segundo Kon (1994, p. 159), “o estabelecimento, em uma região, de disposições legais que podem também influir na macrolocalização da indústria privada apresenta-se sob a forma de isenções ou reduções de impostos locais, incentivos fiscais ou financeiros oferecidos pelo município, códigos de obra, legislação antipoluição, áreas com restrições de gabarito etc., que pesam positiva ou negativamente sobre a escolha da localização da planta".
} 
Tomando a industrialização como elemento fundamental para desenvolver a região, tirando-a de um atraso econômico acumulado década após década, é necessário buscar a gênese do processo industrial no Nordeste - excetuando a industrialização canavieira, que tem sufocado quaisquer outras formas de indústrias e produções agrícolas que não seja a cana com ênfase na sub-região Agreste, mas especificadamente, nas cidades de Arapiraca/AL e Itabaiana/SE.

\section{Industrialização no Agreste: iniciativas locais a partir de Arapiraca e Itabaiana}

Mediante o exposto no item anterior, torna-se necessário trilhar por caminhos diversos no que diz respeito ao processo de industrialização em cidades agrestinas. É preciso ir além dos objetivos proposto pela SUDENE como forma de desenvolver a indústria na região. É trazer à tona as iniciativas locais empresarias, principalmente no interior nordestino, que surgem mediante o espírito de iniciativa do seu povo, com destaque para o agrestino, "pessoas com experiência técnica ou comercial e espírito de iniciativa, [que] contribuíram para a industrialização" (MAMIGONIAN, 1965, p. 70).

As facilidades disponíveis mediante um uso mais diversificado e menos concentração de terras também contribuem para a criação de determinadas indústrias, levando assim, a superar ideias equivocadas pretéritas e entender o que se passa com a economia do Nordeste nas últimas décadas. Nesta empreitada Mamigonian (2009) mostra que,

Ora, Euclides da Cunha desmistificou a imagem do sertanejo nordestino, assim como Gilberto Freyre desmascarou as ideias racistas a respeito do negro e elogiou a miscigenação. Nos últimos tempos os agrestinos tem demostrado que o imobilismo social que paralisou o Nordeste é uma imagem falsa diante da multiplicidade das iniciativas empresariais regionais (MAMIGONIAN, 2009, p. 52).

Os espaços agrestinos constituem espaços mais urbanizados e povoados, onde se encontram os maiores centros populacionais e econômicos do Nordeste (MELO, 1980), com um grande mercado consumidor dos produtos aí produzidos, contribuindo diretamente na evolução econômica e social das cidades localizadas nessa sub-região. O Agreste tem proporcionado variedades no cultivo de produtos alimentares graças a um uso mais diversificado da terra e a força de trabalho em quantidade expressiva, fornecendo para as indústrias existentes matérias-primas diversas como fibras e óleos vegetais em um primeiro momento. Cada Agreste possui suas particularidades, tanto que nos dizeres de Melo (1980, p. 37) “o espaço agrestino possui peculiaridades que, a partir de sua posição geográfica e de seus 
quadros econômicos, lhe conferem um papel estratégico altamente relevante em um planejamento regional que se apoie em relações interespaciais".

O desenvolvimento industrial nas cidades de Arapiraca e Itabaiana, assim como em grande parte do interior nordestino, está muito relacionado com a primeira fase de desenvolvimento industrial do Nordeste, ou seja, dava-se quase que na sua totalidade de forma espontânea e sem nenhum tipo de planejamento. A indústria de tipo local que começa a se desenvolver tem sua gênese baseada fortemente com as iniciativas de pessoas ou grupos locais que conseguiram criar, mesmo que sem um planejamento consolidado, certas indústrias. São negócios que surgem baseando-se na força de trabalho e em iniciativas que não dependem de capital externo nem de mão-de-obra especializada e/ou qualificada para dar início a seus projetos pessoais, que se desdobram em negócios expressivos para a cidade e região, logo, "a iniciativa da industrialização, os industriais e os capitais são locais" (MAMIGONIAN, 1965, p. 64).

Nesse primeiro momento surgem indústrias basicamente através dos poucos investimentos pessoais de algumas pessoas que tinham certos conhecimentos e algumas técnicas, que foram adquiridas de formas diversas, seja de um ou outro ramo industrial. Sendo Arapiraca e Itabaiana as cidades que mais se destacam dentro dos seus estados em relação ao crescimento, tendo no processo industrial uma peça chave, onde ao iniciarem, a maioria não possuía mais que 10 trabalhadores, tendo nos seus quadros de funcionários atualmente 100, 300 e até 1000 trabalhadores, como constatado em trabalho de campo, a partir do Grupo Coringa - Arapiraca/AL, realizado no período da dissertação de mestrado ${ }^{11}$.

Seguindo por este caminho, estes industriais, empresários e comerciantes que aparecem no interior nordestino, podem ser considerados como um tipo de "capitalista sem capital", na medida em que os mesmos "tinham espírito de iniciativa mais ou menos desenvolvido, mas quase nenhum recurso financeiro" (MAMIGONIAN, 1965, p. 78).

Além dos poucos recursos financeiros investidos inicialmente por grande parte das iniciativas industriais locais (nos mais diversos custos: salários, impostos, matérias-primas etc.), têm-se aqueles investimentos advindos de empréstimos, sejam com parentes e amigos, como também, a partir de empréstimos bancários $^{12}$. Isso veio fortalecer e/ou criar novas

\footnotetext{
${ }^{11}$ Ver FIRMINO (2015).

${ }^{12}$ Para Lênin ([1917] 2010, p. 31) “a operação fundamental e inicial que os bancos realizam é a de intermediário nos pagamentos. É assim que eles convertem o capital-dinheiro inativo em capital ativo, isto é, em capital que rende lucro; reúnem toda espécie de rendimentos em dinheiro e colocam-nos à disposição da classe capitalista".
} 
indústrias na cidade, reflexo do que se passava em várias cidades nordestinas que, por sua vez, estavam em grande crescimento.

Os bancos disponibilizam empréstimos que contribuem significativamente para que os pequenos e iniciantes empresários possam seguir com seus projetos primeiros, alavancando de vez suas modestas indústrias, de tal modo que "a quase totalidade das iniciativas dão nascimento, no início, a pequenos estabelecimentos, mesmo se, na origem, o negócio não é exclusivamente familiar" (MAMIGONIAN, 1965, p. 73).

Arapiraca e Itabaiana, antes de suas respectivas emancipações política, possuíam, na feira livre, o seu principal tipo de comércio, movimentando a cidade e toda área ao redor. A feira servia de base para os diversos tipos de negociações, com uma comercialização que já chamava atenção devido à quantidade e variedade de produtos, desde os agrícolas, até os produtos artesanais e os ditos industrializados - mesmo passando por um processo mais artesanal - como a farinha de mandioca e tijolos, que abriram espaço para o começo de uma atividade industrial e para o seu desenvolvimento econômico. Neste sentido, Santos ([1959] 2012, p. 90) mostra que "se, todavia, estatisticamente são considerados industriais, é preciso assinalar que, para a maioria, a fabricação é, sobretudo, o artesanal”.

O processo industrial em cada uma das cidades aqui analisadas teve apoio nos eventos que estavam marcando os períodos históricos das mesmas. Tanto Arapiraca como Itabaiana, tem a feira livre como um desses eventos, já que alguns industriais saíram delas e foram se dedicar a este ramo, a exemplo de Amintas Góes que criou a Gesso Nordeste em Itabaiana. Outros eventos como a cultura do fumo, a produção diversificada de alguns produtos, o crescimento de caminhões, a expansão da urbanização ${ }^{13}$ e, consequentemente, o aumento nas construções entre outros, foram e estão sendo importantes para a consolidação da indústria no interior desses estados, sem falar claro do gado que é responsável aí pelo desenvolvimento da indústria do couro no Nordeste (com produtos como alpercatas, chapéus etc.) e outros produtos fabricados a partir do que o gado proporciona, digam-se o queijo, a manteiga, iogurte etc., produzidos, por exemplo, em Batalha e Major Izidoro em Alagoas. Esses exemplos permitem fazer relação com o que Lênin (1982, p. 173) vinha mostrando, quando afirmava que "as fábricas de queijo e manteiga começaram mesmo a tomar certo aspecto

\footnotetext{
${ }^{13}$ Segundo Souza (1971, p. 38), para se ter uma melhor compreensão da urbanização é imprescindível a "análise dos fatôres históricos, econômicos, políticos, sociais e outros que permitem o aparecimento e o crescimento das cidades. A urbanização será, portanto, a resultante no espaço (paisagem) da dinâmica e da evolução dêsses fatôres".
} 
industrial [...] o leite [...] é comprado aos proprietários das vizinhanças, ou mesmo aos camponeses. Encontram-se queijarias mantidas por todo um grupo de proprietários”.

$\mathrm{O}$ que se nota é a "predominância de pessoas que trabalham por conta própria e empresas familiares cujas atividades abrangem principalmente pequenas fábricas, pequeno comércio" (SANTOS, [1978] 2009, p. 59). Quanto a força de trabalho, se junta a essa afirmativa a proposta de Melo (1980, p. 369), onde em um primeiro momento afirma-se que “o pequeno agricultor proprietário que usa a própria mão-de-obra e a da família sendo, portanto, um participante ao mesmo tempo das categorias dos possuidores de terras e dos grupos que integram a força de trabalho sub-regional”.

No decorrer dos anos, as indústrias começavam a atingir raios maiores de abrangência "e pouco a pouco, conquistaram as localidades vizinhas, englobando assim uma região cada vez mais vasta" (LÊNIN, 1982, p. 220), ultrapassando os limites locais e, até mesmo, regionais e/ou nacionais, levando as mesmas a investirem em melhorias, seja em mão-de-obra - formando trabalhadores para determinado trabalho, aumentando o contingente especializado - como em melhoria de máquinas, transportes, produção etc., o que faz crer que "a industrialização supõe, portanto, a incorporação de novos 'custos de produção', como os transportes de mercadorias, o comércio e custos de consumo, como educação, saúde, transportes de passageiros, diversão etc.”(RANGEL, 2012b, p. 124).

Apesar dessas melhorias, a busca por uma mão-de-obra mais barata é sinônimo de lucro para os grandes empresários e industriais, onde fica claro que "os grandes empresários têm um capital fixo muito maior que os pequenos; entre eles, particularmente, é que se encontram as inovações" (LÊNIN, 1982, p. 257). Verifica-se que,

A abundância de mão-de-obra barata, pouco escolarizada, qualificada ou organizada continua a ser um atrativo mesmo em tempos globalizados. Pode parecer paradoxal que essas características sejam elementos de atração num momento em que os processos de reestruturação têm a qualidade como elemento ideológico básico e se delineia internacionalmente, um perfil de trabalhador caracterizado por alto nível de escolarização e qualificação (LIMA, 1997, p. 143).

À medida que a atividade industrial ia crescendo necessitou-se de um espaço para que recebesse tais indústrias na cidade, o chamado Distrito Industrial/DI. Em Arapiraca o DI (conhecido também como Núcleo Industrial de Arapiraca/NIA), está localizado entre a Rodovia AL-485 e a AL-115, possuindo uma área de 214.916,38 m², com uma distância de $7 \mathrm{~km}$ da área central do município. O DI tem servido de sustentação no processo de industrialização que vem avançando, visto mediante indústrias dos mais variados ramos. 
As empresas, que se instalam no DI ou que se deslocam de outras áreas, são beneficiadas, com incentivos fiscais, concessão de lotes, apoio técnico e com uma boa infraestrutura (água, luz, telefonia, transporte etc.). Segundo a Prefeitura Municipal de Arapiraca (2013), existiam naquele ano 13 indústrias instaladas e funcionando no DI e que contribuíam direta e indiretamente na geração de empregos e, consequentemente, na economia da cidade. A tabela 1 apresenta as indústrias localizadas no DI, o que cada uma produz e o quantitativo de empregos gerados por elas.

Tabela 1 - Arapiraca/AL: empresas localizadas no Distrito Industrial/DI (2013)

\begin{tabular}{|c|c|c|c|c|}
\hline \multirow{2}{*}{ Empresas } & \multirow{2}{*}{ Produção/Atividade } & \multicolumn{3}{|c|}{ EMPREGOS } \\
\hline & & Diretos & Indiretos & Total \\
\hline Coca-Cola & Refrigerante em geral, pet e garrafa & 123 & 369 & 492 \\
\hline $\begin{array}{c}\text { SAMPLAS - Indústria e Comércio de Plástico } \\
\text { LTDA }\end{array}$ & Artefatos de plásticos para embalagem & 40 & 120 & 160 \\
\hline $\begin{array}{l}\text { INCOGRAF - Indústria e Comércio de Produtos } \\
\text { Gráficos }\end{array}$ & $\begin{array}{l}\text { Formulários, bobina, embalagens e } \\
\text { artigos gráficos }\end{array}$ & 40 & 120 & 160 \\
\hline $\begin{array}{l}\text { ASA BRANCA - Indústria Comercial e } \\
\text { Importação LTDA }\end{array}$ & $\begin{array}{c}\text { Industrialização de peixes, crustáceos e } \\
\text { moluscos }\end{array}$ & 228 & 684 & 912 \\
\hline $\begin{array}{c}\text { CONCRENORTE - Concreto do Nordeste } \\
\text { LTDA }\end{array}$ & Fabricação de postes, galpões e pontes & 55 & 169 & 224 \\
\hline Transportadora Jolivan & Transporte de produtos diversos & 60 & 180 & 240 \\
\hline MULTISERV Logística & Prestação de serviços em geral & 45 & 135 & 180 \\
\hline Dinâmica Distribuidora & Produtos diversos & 50 & 130 & 180 \\
\hline Laticínio Góis & $\begin{array}{l}\text { Fabricação de produtos derivados do } \\
\text { leite e iogurte }\end{array}$ & 19 & 57 & 76 \\
\hline A. J. Costa - Aryane Estofados & Móveis e estofados & 60 & 180 & 240 \\
\hline Redimix Potiguar & Enchimento de lajes, fundação, piso etc. & 60 & 180 & 240 \\
\hline MULTISERV Logística (duplicação) & Prestação de serviços em geral & 100 & 300 & 400 \\
\hline & TOTAL DE EMPREGOS & 876 & 2.628 & 3.504 \\
\hline
\end{tabular}

Fonte: PREFEITURA MUNICIPAL DE ARAPIRACA/AL. Perfil Arapiraca/AL 2. Secretaria Municipal de Indústria, Comércio e Serviços. 2013.

Existem diversas outras indústrias espalhadas pela cidade, que não tem localização no DI. São indústrias que trabalham com PVC, café e derivados do milho, metalurgia, embalagens plásticas (Araforros: indústria de forros; Grupo Mibasa: mineração; CILEL: prémoldados; FARPLAST: indústria de embalagens plásticas; Proteica Alimentos LTDA: ração para cães e gatos). Assim,

Com a criação de incentivos para que as empresas viessem a se instalar no Município e a construção do Núcleo Industrial de Arapiraca, a cidade que foi voltada para o campo diversificou sua economia e atualmente beneficia e exporta mercadorias, com destaque para produção de PVC, alimentos e móveis (PREFEITURA MUNICIPAL DE ARAPIRACA/AL, 2013, p. 25).

Chama atenção para o Polo Moveleiro do Agreste, denominado de Polo de Madeira e Móveis Nascimento Leão, que tem por objetivo, 
Fomentar a produção moveleira em todo o Estado. É dotado de infraestrutura e diversos incentivos que beneficiam a todos que compõem a cadeia produtiva da madeira, como marceneiros e proprietários de empresas de pequeno porte, empresas fornecedoras de insumos e matérias-primas. Possui cerca de $96 \mathrm{mil} \mathrm{m}^{2}$, dividido em 45 lotes (PREFEITURA MUNICIPAL DE ARAPIRACA/AL, 2012, p. 91).

Em Itabaiana o DI está localizado na BR-235 nas proximidades da cidade. De acordo com dados obtidos na Secretaria de Finanças da Prefeitura Municipal da cidade, no ano de 2013, existiam 8 empresas em funcionamento com benefícios do governo do Estado (tabela 2), 4 empresas beneficiadas com obras iniciadas (tabela 3), 5 beneficiadas e obras ainda não iniciadas (tabela 4). Dentre as já instaladas pode-se citar a Costa \& Silva (em funcionamento desde 2014), fábricas de panelas e fábricas de joias, neste último caso chama atenção para a cadeia que começa a criar força na cidade, e são empresas totalmente itabaianenses.

Tabela 2 - Itabaiana/SE: empresas em funcionamento beneficiadas pelo Governo do Estado

\begin{tabular}{c|c|c|c|c}
\hline Empresa & Atividade & $\begin{array}{c}\text { Mão-de-obra } \\
\text { Atual }\end{array}$ & $\begin{array}{c}\text { Mão-de-obra } \\
\text { Projetada }\end{array}$ & Incentivo \\
\hline Danko do Nordeste Industrial LTDA & Alimentício & 28 & 28 & Fiscal e Locacional \\
\hline Indústria de Alumínio Serrana LTDA & $\begin{array}{c}\text { Artefatos de } \\
\text { Alumínio }\end{array}$ & 11 & 27 & Fiscal e Locacional \\
\hline K3 Distribuidora e Laboratório Óptico LTDA & Artigos Ópticos & 17 & - & Fiscal e Locacional \\
\hline Curtume Margem da Serra LTDA & Curtume & 70 & 70 & Fiscal e Locacional \\
\hline $\begin{array}{c}\text { GIAL Grupo Industrial de Alimentos LTDA } \\
\text { (Vinagre Carícia) }\end{array}$ & Alimentício & 56 & 56 & Fiscal \\
\hline Serrana Têxtil S/A & Têxtil & 3 & 60 & Fiscal \\
\hline Pedreira São José & $\begin{array}{c}\text { Minerais não } \\
\text { Metálicos }\end{array}$ & 22 & - & Fiscal \\
\hline Dinâmica Mármores e Granito LTDA & $\begin{array}{c}\text { Minerais não } \\
\text { Metálicos }\end{array}$ & 9 & - & Locacional \\
\hline
\end{tabular}

Fonte: Secretaria de Finanças da Prefeitura Municipal de Itabaiana (2013). Elaboração: FIRMINO, P. C. S.

Tabela 3 - Itabaiana/SE: empresas beneficiadas/obras iniciadas

\begin{tabular}{c|c|c|c|c|c}
\hline Empresa & Atividade & $\begin{array}{c}\text { Investimento } \\
\mathbf{( R \mathbf { 1 . 0 0 0 , 0 0 } )}\end{array}$ & Empregos & Incentivo & Ano \\
\hline Itabaiana Massas Indústria LTDA ME & Alimento & $\mathrm{R} \$ 782,00$ & 23 & Locacional & 2010 \\
\hline Braspet Reciclagem LTDA & Reciclagem & $\mathrm{R} \$ 1.711,00$ & 41 & Fiscal e Locacional & 2010 \\
\hline $\begin{array}{c}\text { Costa \& Silva Fabricação de Artefatos de } \\
\text { Cimento LTDA }\end{array}$ & $\begin{array}{c}\text { Artefatos de } \\
\text { Cimento }\end{array}$ & $\mathrm{R} \$ 1.253,00$ & 42 & Fiscal e Locacional & 2011 \\
\hline $\begin{array}{c}\text { Indústria de Agregados Massa Fácil } \\
\text { LTDA - ME }\end{array}$ & $\begin{array}{c}\text { Minerais não } \\
\text { Metálicos }\end{array}$ & $\mathrm{R} \$ 382,00$ & 15 & Locacional & 2011 \\
\hline
\end{tabular}

Fonte: Secretaria de Finanças da Prefeitura Municipal de Itabaiana (2013). Elaboração: FIRMINO, P. C. S. 
Tabela 4 - Itabaiana/SE: empresas beneficiadas/obra não iniciada

\begin{tabular}{|c|c|c|c|c|c|}
\hline Empresa & Atividade & $\begin{array}{l}\text { Investimento } \\
(\mathbf{R} \$ 1.000,00)\end{array}$ & Empregos & Incentivo & Ano \\
\hline $\begin{array}{l}\text { São Lucas Carpintaria e } \\
\text { Marcenaria LTDA - ME }\end{array}$ & $\begin{array}{c}\text { Fabricação de } \\
\text { Esquadrarias de Madeira }\end{array}$ & $\mathrm{R} \$ 715,00$ & 15 & Locacional & 2012 \\
\hline Kiara Smi-Joias - ME & Fabricação de Folhados & $\mathrm{R} \$ 265,00$ & 23 & Fiscal e Locacional & 2012 \\
\hline $\begin{array}{l}\text { LF Indústria e Comércio de } \\
\text { Mármore e Granitos LTDA - } \\
\text { ME }\end{array}$ & $\begin{array}{c}\text { Produtos de Mármore e } \\
\text { Granito }\end{array}$ & $\mathrm{R} \$ 569,00$ & 7 & Locacional & 2012 \\
\hline $\begin{array}{l}\text { Indústria de Gesso Gessolar } \\
\text { LTDA }\end{array}$ & Minerais não Metálicos & $\mathrm{R} \$ 502,00$ & 14 & Locacional & 2012 \\
\hline $\begin{array}{l}\text { Sobral Indústria Comércio e } \\
\text { Serviços LTDA }\end{array}$ & Construção Civil & $\mathrm{R} \$ 870,00$ & 12 & Fiscal e Locacional & 2012 \\
\hline
\end{tabular}

Entretanto, vale aqui destacar que além desses distritos existem várias outras indústrias espalhadas na cidade, não sendo possível dizer que a zona industrial dessas cidades está circunscrita apenas no DI e muito menos na zona urbana, isso porque, a presença de indústria na zona rural também é uma realidade, atraindo para essa área uma população que aí se aglomera, agregando-a com o passar do tempo na zona urbana da cidade, como a Cerâmica Higino que em seu início estava localizada na zona rural de Itabaiana, e com a expansão da zona urbana, passou a integrar essa parte da cidade, levando a perceber que "grande parte dos estabelecimentos industriais precedeu a formação de uma verdadeira aglomeração urbana. Ora, isto explica a presença de várias indústrias no centro e na periferia do centro atual" (MAMIGONIAN, 1965, p. 136).

Diante do exposto, acredita-se que as duas cidades começaram a se tornar área de atração de industriais e comerciantes de várias localidades que enxergam aí um meio de implantarem e desenvolverem seus negócios, uma vez que, à medida que vão obtendo lucro vão reinvestindo nos seus pequenos negócios e/ou em outros ("produzir o máximo em quantidade, segundo a política de reinvestimentos maciços dos lucros em renovação de máquinas [por exemplo]" (MAMIGONIAN, 1965, p. 90)), sejam no mesmo ramo ou em ramos que estejam em expansão na cidade.

Observa-se que o aumento nos lucros deve-se a um mercado consumidor de produtos manufaturados que vem crescendo no interior das principais cidades agrestinas (graças também ao contingente populacional que tem aumentado nas últimas décadas) e que se estendem as demais cidades, não só no estado como para os demais estados nordestinos e também para outras regiões, valorizando cada vez mais os produtos locais e investindo na produção de acordo com o gosto desses consumidores, além é claro da qualidade que se deve 
ter para manter-se no mercado e não ser derrubado pelas concorrências vorazes, a maioria advinda de outras regiões e/ou países.

\section{O processo industrial em Arapiraca}

A cidade de Arapiraca desde quando povoado já dialogava e mantinha um bom relacionamento com a sua vizinhança, apoiada em atividades agrícolas, na feira livre e no comércio que estava em formação. Entre as décadas de 1920 e 1940, com a transformação da mandioca em farinha e em seguida do fumo em folha para fumo de rolo, é que se notam os primeiros indícios da atividade industrial na cidade.

O processo de industrialização de Arapiraca, quase confundido com um trabalho mais artesanal, tem início antes mesmo de se pensar na criação da SUDENE. Por volta da década de 1920 já existia na cidade diversas casas de farinha ${ }^{14}$, que transformavam a mandioca cultivada em farinha, mediante um processo que se dava de forma tradicional e com pouca maquinaria. Nesse período era difícil estabelecer uma distinção entre a pequena indústria nascente e o artesanato,

O artesanato destina-se a atender a um mercado local utilizando um mínimo de maquinaria e de técnica, sendo dirigido por empresários que não têm uma maior informação sobre as técnicas administrativas, empregando geralmente, pequeno número de trabalhadores por estabelecimento - quase sempre menos de cinco (ANDRADE, 1974, p. 116).

Junto com a mandioca existia o cultivo do algodão ${ }^{15}$ e outros produtos que passaram a integrar a economia da cidade, atraindo novos investimentos e fábricas, principalmente, depois da forte concentração da cultura fumageira, que intensificou seu cultivo a partir dos anos de 1940, ultrapassando a mandioca e ocupando posto de principal produto cultivado em Arapiraca. Juntamente com Coité do Nóia e Lagoa da Canoa, constituíram a Região Fumageira do Agreste Alagoano. Contudo, a cidade de Arapiraca é a que sobressai, com uma mancha territorial bem significativa.

Segue-se o de Lagoa da Canoa, colocada, a longa distância, em segundo lugar. Os quatro municípios que se seguem são os de Jirau do Ponciano, Feira Grande, São Sebastião e Igaci. Com produções menores, também integram a área em causa os de Taquarana, Limoeiro de Anadia e Coité do

\footnotetext{
${ }^{14}$ Andrade (1974, p. 118), mostra que a produção de alimentos "tem importância devido à grande quantidade de 'casas de farinha' que beneficiam a mandioca, fornecendo à população rural a farinha e a goma”.

${ }_{15}$ Conforme Andrade (1998, p. 144), "industrialização mais barata e menos urgente que a da cana colocou o beneficiamento do algodão na mão de comerciantes que, com suas bolandeiras, a princípio, e seus descaroçadores depois, estabeleciam-se em cidades, vilas, e povoações, passando a comprar a matéria-prima ao agricultor para vendê-la, após o beneficiamento, aos exportadores".
} 
Nóia, onde o fumo participa com certa expressividade das combinações agrícolas respectivas (MELO, 1980, p. 274).

Arapiraca, como principal cidade do interior alagoano e segunda cidade de maior importância para o estado, criou o seu distrito industrial, oferecendo subsídios ${ }^{16}$ às indústrias que tivessem interessadas em se instalarem em terras arapiraquenses. Passou então a sofrer mudanças significativas, de uma indústria surgida mediante um capital e mão-de-obra local, para a instalação de indústrias de fora preocupadas apenas em usufruir dos benefícios que lhes foram dados, como matéria prima, mão-de-obra barata, infraestrutura, energia, transporte etc.

Em relação às observações feitas inicialmente no que concernem as indústrias tipicamente arapiraquenses, percebe-se uma forte presença da indústria voltada ao ramo alimentício - e que tiveram sua gênese mediante investimentos locais em força de trabalho, capital, maquinaria etc. Cita-se o Grupo Coringa (alimentos diversos), Trigo e CIA (panificação), Vinagre Camarão (vinagres e molhos) e Popular Alimentos (doces e salgados). Outras além do ramo alimentício podem ser citadas como a Araforros (PVC), CILEL (artefatos de concretos), Merconplas (materiais plásticos) etc.

A Indústria Vinagre Camarão pertence ao Grupo Zezinho Galdino, que abrange também a empresa de ônibus Real Arapiraca e lojas de peças (Auto Peças Real). A Vinagre Camarão e as demais são exemplos de indústrias nascidas e desenvolvidas na cidade, que ao longo do tempo contribuíram para o desenvolvimento econômico de Arapiraca. Para alcançar esse patamar, Mamigonian (1965, p. 97) diz que "justamente estas grandes famílias compreenderam muito bem a política financeira que conduz ao desenvolvimento econômico: elas aplicaram cuidadosamente, nos seus negócios, a retenção máxima dos lucros”.

Dentre essas indústrias a mais antiga de que se tem notícia é a Indústria Vinagre Camarão, nascida no ano de 1943 nas proximidades do Centro da cidade, hoje localizada às margens da zona urbana, no bairro Batingas. Na sequência tem-se o Grupo Coringa de 1969 (com sua primeira instalação no bairro Primavera, zona urbana de Arapiraca) e a Popular Alimentos de 1975 (com localização inicial no bairro Alto do Cruzeiro, zona urbana de Arapiraca). Atualmente encontram-se instaladas, respectivamente, no bairro Planalto em Arapiraca e Distrito Industrial da cidade de Limoeiro de Anadia/AL.

\footnotetext{
${ }^{16}$ Para Wallerstein (2001, p. 47), através de diversas taxações "os governos têm sido capazes de reunir grande quantidade de capital, que têm redistribuído para pessoas ou grupos, já grandes detentores de capital, através de subsídios".
} 
Posteriormente surgiram outras pequenas indústrias, assim como as já existentes foram crescendo e aumentando seus espaços e sua produção ${ }^{17}$, bem como o número de trabalhadores (em relação ao número de pessoas empregadas, juntas Coringa, Merconplas e Popular Alimentos são responsáveis por empregar aproximadamente 1943 pessoas), precisando deslocar-se para áreas maiores, de forma a atender suas necessidades.

Chama atenção o fato de várias indústrias estarem localizadas nas proximidades do Centro, fato decorrente da limitação do perímetro urbano, o que não abrangia as referidas indústrias. Atualmente, por estarem presentes na zona urbana acabam muitas vezes não tendo espaço para expandirem suas áreas, o que leva a um deslocamento para zona rural e/ou mesmo para outras cidades, como é o caso da indústria Popular Alimentos que se deslocou para zona rural da cidade de Limoeiro de Anadia/AL.

Destarte, foi possível constatar o grau de importância que elas têm - como indústrias nascidas a partir de iniciativas locais - não somente para a cidade e região, como para todo o estado.

\section{$O$ processo industrial em Itabaiana}

Dentro do Agreste Sergipano destacam-se as Microrregiões de Itabaiana e Lagarto, sendo as duas mais ricas do ponto de vista agrícola e, mais recentemente, do ponto de vista dos serviços e comércio, além é claro da indústria, com destaque para aquelas de tipos familiares. Itabaiana se destaca com a policultura ${ }^{18}$, assim como Lagarto com o cultivo do fumo e da laranja ${ }^{19}$, fruta esta também cultivada em grande escala na Bahia, "estados com tradição na produção dessa fruta nobre, consumida em larga escala nas cidades da região" (ANDRADE; ANDRADE, 1999, p. 98).

Itabaiana é grande produtora e exportadora da produção hortícola, graças a um mercado consumidor favorável e a médias e pequenas propriedades existentes na cidade, levando-a, devido a suas características particulares, a possuir importância destacada no interior sergipano, tanto pela numerosa população que sustenta como pela função que exerce, de cinturão verde de Aracaju (MELO, 1980).

\footnotetext{
${ }^{17}$ Aumentar a produção é, ao mesmo tempo, de acordo com Rangel (2012, p. 141), "causa e efeito primários do desenvolvimento econômico [...]. O desenvolvimento econômico tem origem, não no processo de produção [...] mas no processo de distribuição que é efeito estritamente social, porque diz exclusivamente respeito às relações entre os homens".

${ }^{18}$ Entre os produtos de lavouras permanentes produzidos em Itabaiana, destacam-se, principalmente, manga, banana, laranja, coco da baía e maracujá. Em 2010 a produção de manga ficou em 1.672 toneladas, a de banana rendeu 880 toneladas, laranja obteve 405 toneladas, o coco da baía 156 mil frutos e o maracujá 80 toneladas.

19 "Não sendo possível precisar ali até onde cada uma dessas formas de uso da terra é invasora ou invadida, parece certo que elas se interpenetram, a laranja entrando pelas terras do fumo e o fumo entrando pelas terras da laranja" (MELO, 1980, p. 342).
} 
Apesar de Itabaiana ganhar destaque no interior do estado de Sergipe, ela não é o centro urbano de maior importância, mas sim um dos centros de destaques. Ela sobressai, e aí se torna centro principal e referência, no que toca alguns aspectos, como a produção hortícola e a atividade industrial crescente. Itabaiana é a cidade mais importante do estado, no que se refere à indústria ceramista e a carrocerias para caminhões, que têm sua gênese atrelada as formas artesanais no que diz respeito à fabricação dos seus produtos, o que se deve as várias olarias espalhadas pela zona rural e urbana, assim como as pequenas serralharias que deram origem as fábricas de carrocerias, onde "a produção de carrocerias para caminhões é tão antiga quanto a existência dos caminhões com carrocerias em madeira" (BISPO, 2013, p. 36).

Neste último caso é possível afirmar que as fábricas de carrocerias tiveram sua gênese a partir do aumento no número de caminhões na cidade, sendo ela a cidade sergipana que mais tem caminhão proporcionalmente por habitante, de tal modo que,

A presidente da República, Dilma Rousseff sancionou a Lei de número 13.044 que concede ao município de Itabaiana o título de 'Capital Nacional do Caminhão'. A lei entrou em vigor no dia 20 de novembro de 2014, após a publicação no Diário Oficial da União. A lei visa valorizar simultaneamente, o caminhoneiro, o caminhão e a cidade de Itabaiana (REVISTA ITABAIANA, 2015, p. 17).

Levando-se em consideração que a cidade de Itabaiana é tida como a Capital Nacional do Caminhão, o que a fez desenvolver vários tipos de atividades e serviços relacionados com o mesmo, pode-se apontar a grande importância que têm os caminhoneiros e os caminhões na cidade. Por um lado eles têm destaque na realização da feira livre, por outro eles foram e são fundamentais para as indústrias de carrocerias, o que pode ser visto mediante a quantidade delas espalhadas por toda a cidade, destacando a Fábrica de Carroceria São Carlos LTDA, Madeireira e Fábrica de Carrocerias LTDA, Fábrica de Carroceria São José LTDA ${ }^{20}$, levando a Mendonça (2012, p. 29), fazer a seguinte indagação: “o que seria das feiras livres, dos supermercados e do comércio em geral se não houvesse o caminhão? Com certeza uma estagnação econômica".

As poucas indústrias itabaianenses, nascidas muito modestamente, contavam e ainda contam com uma mão-de-obra em sua maioria familiar; com técnicas mais artesanais misturadas com técnicas sofisticadas e modernas; com a matéria-prima empregada advinda de povoados da cidade, de cidades próximas e em menor proporção de outros estados e regiões.

\footnotetext{
${ }^{20}$ De acordo com dados do Guia Perfil do Comércio (2015), além dessas três indústrias têm-se a Madeireira e Carroceria União, Indústria de Carrocerias Barbosa, Fábrica de Carroceria Nossa Senhora da Conceição, Fábrica de Carroceria Filho, Fábrica de Carrocerias Estrela, Carroceria Irmãos Santana e Carroceria Estrela.
} 
As primeiras indústrias de que se têm notícias datam da metade do século $\mathrm{XX}$ (neste caso não se inclui as olarias). A primeira surgiu em 1950 - Indústrias Reunidas Fontes LTDA - e ainda mantem-se em pleno funcionamento; a segunda data de 1957 - Fábrica Nossa Senhora da Conceição (a pioneira em carrocerias para caminhões e que pertencia a Antônio Lauro Moura) - mas, foi praticamente extinta, existindo apenas uma serralheria em seu lugar; e uma terceira e que ainda prevalece fortemente na cidade é a Indústria Nova Aurora de Artefatos de Cimento LTDA de 1962. Outras foram surgindo com o passar do tempo: Cerâmica Higino e Cerâmica Mandeme de 1965, Cerâmica Batula de 1983, Carrocerias São Carlos, União e São José, criadas em 1982, 1985 e 1988, respectivamente.

No início a produção destinava-se quase que predominantemente para o consumo da própria cidade e região, hoje atinge um raio de abrangência que ultrapassa os limites regionais, chegando até a região Sul do Brasil. Seguindo as observações de Mamigonian (1965, p. 73), nota-se que "a quase totalidade das iniciativas dão nascimento, no início, a pequenos estabelecimentos, mesmo se, na origem, o negócio não é exclusivamente familiar".

Portanto, nota-se que estes são os ramos principais e, que contribuem, significativamente, no processo industrial da cidade de Itabaiana, destacando, aquelas unidades industriais que tiveram suas gêneses fortemente atreladas às iniciativas locais, a exemplo dos ramos de construção, ceramista e transporte (as fábricas de carrocerias).

\section{Algumas conclusões}

O desenvolvimento econômico nordestino, com particular atenção para as cidades de Arapiraca e Itabaiana na sub-região Agreste de Alagoas e Sergipe, respectivamente, tem suas raízes fortemente atreladas às pessoas que, com espírito de iniciativa e desejo de vencer, utilizaram-se das oportunidades e dos poucos recursos financeiros para criarem seus pequenos negócios e se fixarem, posteriormente, como os grandes empresários da região. Com o passar do tempo os pequenos negócios desdobram-se em empresas, fábricas e indústrias, mostrando que o "seu dinamismo econômico está estreitamente ligado ao dinamismo da população" (SANTOS, [1980] 2010, p. 139).

Portanto, essas cidades têm constituídos centros dinâmicos não só dos estados as quais pertencem, mas também do Agreste e de toda a região Nordeste. Logo, o caráter singular dessas cidades, o que pode ser visto em várias outras no interior nordestino, vem mostrar que o processo de industrialização começou a ocupar certo espaço, tanto as indústrias locais, como aquelas de grupos econômicos não regionais, fortalecendo e expandindo as atividades de bens e serviços, bem como ampliando o comércio já existente. Assim, Arapiraca e 
Itabaiana demostram que o surgimento de uma atividade industrial, baseada em iniciativas locais é uma realidade verídica e que tem crescido em paralelo as atividades voltadas para os serviços e comércios, sendo, isto, uma particularidade destas cidades interioranas.

\section{Referências Bibliográficas}

ANDRADE, M. C. de. Espaço, polarização e desenvolvimento: a teoria dos pólos de desenvolvimento e a realidade nordestina. Recife: Centro Regional de Administração Municipal - CRAM, Editora Brasiliense, $2^{\mathrm{a}}$ ed. 1970a.

Geografia econômica do Nordeste: o espaço e a economia nordestina. São Paulo: Editora Atlas S. A., $2^{\mathrm{a}}$ ed., 1974.

A Terra e o Homem no Nordeste: contribuição ao estudo da questão agrária no Nordeste. $6^{\mathrm{a}}$ ed. São Paulo: Cortez, 1998.

O Nordeste e a questão regional. São Paulo: Editora Ática S.A. $2^{\text {a }}$ ed., 1993.

ANDRADE, M. C. de.; ANDRADE, S. M. C. de. A Federação Brasileira: uma análise geopolítica e geo-social. São Paulo: Contexto, 1999.

ARAÚJO, T. B. de. Industrialização do Nordeste: intenções e resultados. In: MARANHÃO, S. (org.) A Questão Nordeste: Estudos sobre formação histórica, desenvolvimento e processos políticos e ideológicos. Rio de Janeiro: Paz e Terra, pp. 71-82, 1984.

Herança de diferenciação e futuro de fragmentação. Dossiê Nordeste I. Estudos Avançados 11 (29), 1997.

BISPO, J. de A. Itabaiana, Nosso Lugar: quatro séculos depois. Aracaju: Infographics, 2013, 268p.

FIRMINO, P. C. S. Arapiraca/AL e Itabaiana/SE - a feira livre como gênese e desenvolvimento de dois centros regionais do interior do Nordeste brasileiro. 2015, $306 \mathrm{f}$. Dissertação (Mestrado) - Faculdade de Filosofia, Letras e Ciências Humanas/FFLCH, Universidade de São Paulo, São Paulo, 2015.

FURTADO, C. A saga da Sudene: (1958-1964). Rio de Janeiro: Contraponto. Centro Internacional Celso Furtado de Políticas para o Desenvolvimento, 2009. il. - (Arquivos Celso Furtado; v. 3). 283p.

GUIA PERFIL DO COMÉRCIO. Itabaiana, 100 coisas para fazer. Itabaiana, $10^{\mathrm{a}}$ ed., 2015.

KOM, A. Economia industrial. Nobel, 1994.

LÊNIN, V. I. O desenvolvimento do capitalismo na Rússia - o processo de formação do mercado interno para a grande indústria. Tradução de José Paulo Netto e revisão, com base no original russo, por Paulo Bezerra. São Paulo: Abril Cultural, 1982.

O imperialismo, fase superior do capitalismo. Tradução de Leila Prado. São Paulo. Centauro, $4^{a}$ ed., $1^{a}$ reimpressão, [1917] 2010. 128p. 402p.

LIMA, J. C. Negócios da China: a nova industrialização do Nordeste. Revista Novos Estudos/ CEBRAP. São Paulo, n. 49, p. 141-158, novembro, 1997.

MAMIGONIAN, A. Estudo geográfico das indústrias de Blumenau. Revista Brasileira de Geografia, Rio de Janeiro: Secretaria de Planejamento e Coordenação da Presidência da República, Fundação Instituto Brasileiro de Geografia e Estatística - IBGE, v. 27, no 3, pp. 389-482, 1965.

O Nordeste e o Sudeste na divisão regional do Brasil. Geografia Econômica Anais de Geografia Econômica e Social. Grupo de Pesquisa/CNPq Formação Sócio- 
Espacial: Mundo, Brasil e Regiões. Universidade Federal de Santa Catarina. Florianópolis: Impressão no Departamento de Geociências, abril de 2009.

MELO, M. L. de. Os Agrestes: estudo dos espaços nordestino do sistema gado-policultura de uso de recursos. Recife: Ministério do Interior - SUDENE, Superintendência Adjunta de Planejamento - Coordenação de Planejamento Regional, Divisão Política Especial - Estudos Regionais 4, 1980.

MENDONÇA, C. Vidas em trânsito - a surpreendente e emocionante história dos caminhoneiros. Itabaiana/SE, 2012. 60p.

PREFEITURA MUNICIPAL DE ARAPIRACA/AL. Plano decenal de Arapiraca: desenvolvimento territorial sustentável no Agreste alagoano. Secretaria Municipal de Planejamento. Arapiraca, 2012.

2013.

Perfil Arapiraca/AL 2. Secretaria Municipal de Indústria, Comércio e Serviços.

PREFEITURA MUNICIPAL DE ITABAIANA/SE. Dados socioeconômicos de Itabaiana 2012. Secretaria de Planejamento e do Desenvolvimento Sustentável (SEPES). Itabaiana, 2012.Secretaria de Finanças da Prefeitura Municipal de Itabaiana (2013).

RANGEL, I. Financiamento dos empreendimentos regionais. Anais do Seminário para o Desenvolvimento do Nordeste. Garanhuns: Confederação Nacional da Indústria, Serviço Social da Indústria - Divisão de Estudos e Planejamento, v. II, pp. 419-459, 1959.

Dualidade básica da economia brasileira. In: . Obras reunidas/Ignácio

Rangel. v. I. Rio de Janeiro: Contraponto: Centro Internacional Celso Furtado de Políticas para o Desenvolvimento, 2012, 2v. (1.508p.). pp. 285-353.

Introdução ao desenvolvimento econômico brasileiro (1955). In: Obras reunidas/Ignácio Rangel. v. I. Rio de Janeiro: Contraponto: Centro Internacional Celso Furtado de Políticas para o Desenvolvimento, 2012a, 2v. (1.508p.). pp. 129-202.

O desenvolvimento econômico no Brasil (1954). In: Obras reunidas/Ignácio Rangel. v. I. Rio de Janeiro: Contraponto: Centro Internacional Celso Furtado de Políticas para o Desenvolvimento, 2012b, 2v. (1.508p.). pp. 39-128.

REVISTA ITABAIANA. Essa é nossa. Itabaiana: Editora Itabaiana, ano II, $\mathrm{n}^{\circ} 2$, jan/fev., 2015.

SANTOS, M. O centro da cidade do Salvador: estudo de Geografia Urbana. São Paulo: Editora da Universidade de São Paulo/EDUSP, 2a ed. 1 reimpr. [1959] 2012 - (Coleção Milton Santos; 13). 208p.

Pobreza urbana. São Paulo: Editora da Universidade de São Paulo/EDUSP, 3. ed. [1978] 2009 - (Coleção Milton Santos; 16). 136p.

A urbanização desigual: a especificidade do fenômeno urbano em países subdesenvolvidos. São Paulo: Editora da Universidade de São Paulo/EDUSP, 3. ed. [1980] 2010 - (Coleção Milton Santos; 18). 144p.

SOUZA, M. D. A. de. Paraná: o quadro geográfico, histórico e econômico do processo de urbanização. Boletim Paulista de Geografia - Associação dos Geógrafos Brasileiros/AGB, São Paulo, nº 46, pp. 38-87, dez. 1971.

WALLERSTEIN, I. Capitalismo histórico e civilização capitalista. Tradução de Renato Aguiar e revisão de César BenJamin e Immanuel Wallerstein. Rio de Janeiro: Contraponto, 2001. 144p.

Recebido em 05 de abril de 2018.

Aceito em 04 de junho de 2018. 